Ming Zuo $\cdot$ Hisahide Nishio $\cdot$ Myeong Jin Lee

Kenji Maejima $\cdot$ Sigenobu Mimura $\cdot$ Kimiaki Sumino

\title{
The C677T mutation in the methylene tetrahydrofolate reductase gene increases serum uric acid in elderly men
}

\begin{abstract}
A common mutation, C677T, in the methylene tetrahydrofolate reductase gene (MTHFR) reduces the activity of MTHFR and increases total homocysteine levels in plasma. Increased homocysteine levels are reportedly associated with high serum uric acid levels. The relationship between the MTHFR mutation and uric acid metabolism remains unclear, however. To investigate whether the C677T MTHFR mutation is a risk factor for hyperuricemia, we performed MTHFR genotyping and clinical laboratory determinations, including serum uric acid, in 271 elderly Japanese men (age range, 40-79 years; mean, 52.6 years). The mean uric acid levels for the $\mathrm{C} / \mathrm{C}, \mathrm{C} / \mathrm{T}$, and $\mathrm{T} / \mathrm{T}$ genotypes were $5.67,6.00$, and $6.39 \mathrm{mg} / \mathrm{dl}$, respectively $(P=$ $0.012)$. The $T / T$ genotype was more frequent in subjects with high uric acid levels than in those with low uric acid levels $(P=0.038)$. These findings suggest that the C677T MTHFR mutation contributed to higher uric acid levels in subjects enrolled in this study. In conclusion, the mutation of the MTHFR gene may be a risk factor for hyperuricemia in elderly men.
\end{abstract}

Key words MTHFR $\cdot$ Homocysteine $\cdot$ Uric acid

\section{Introduction}

Methylene tetrahydrofolate reductase (MTHFR) is a regulating enzyme in the remethylation phase of homocysteine metabolism. A common mutation in the MTHFR gene (a C-to-T transition at nucleotide position 677) has been reported as a genetic risk factor for cardiovascular disease in Western countries (Frosst et al. 1995; Christensen et al. 1997). The mutation has also been reported to be common

M. Zuo $\cdot$ H. Nishio $(\bowtie) \cdot$ M.J. Lee $\cdot$ K. Sumino

Department of Public Health, Kobe University School of Medicine

7-5-1 Kusunoki-cho, Chuo-ku, Kobe 650-0017, Japan

Tel. +81-78-382-5541; Fax +81-78-382-5559

e-mail: nishio@med.kobe-u.ac.jp

K. Maejima $\cdot$ S. Mimura

Hyogo Health Service Association, Kobe, Japan in the Japanese population and to be related to the occurrence of cardiovascular diseases (Nishio et al. 1996; Morita et al. 1998; Ou et al. 1998). The C677T MTHFR mutation converts an alanine to a valine residue in the MTHFR protein; this amino acid substitution decreases the activity of the enzyme, leading to high plasma homocysteine levels (Frosst et al. 1995; van der Put et al. 1995, 1996; Christensen et al. 1997; Gudnason et al. 1998; van der Put et al. 1998). Several lines of evidence indicate that plasma homocysteine is an independent risk factor in cardiovascular disease (Scott and Weir 1996) and stroke (Coull et al. 1990).

Hyperhomocysteinemia can result from genetic or nutrient-related disturbances of homocysteine metabolism. A significant positive correlation between plasma homocysteine and serum uric acid has been reported in patients with atherosclerosis and in control subjects (Kang et al. 1986; Araki et al. 1989; Coull et al. 1990; Malinow et al. 1995; Evers et al. 1997; Motti et al. 1998). Motti et al. (1998) found a relationship between the C677T MTHFR mutation and serum uric acid. Their data, however, were for an inseparable mixture of young and old, and men and women, in spite of the higher uric acid levels found in men (Reed et al. 1972; Brand et al. 1985; Freedman et al. 1995).

In this study, to investigate whether the C677T MTHFR mutation is a risk factor for hyperuricemia, we performed MTHFR genotyping analysis and clinical laboratory determinations, including serum uric acid, in elderly Japanese men.

\section{Methods}

Study population

Two hundred and seventy-one unrelated men aged 40 years or more were recruited into the study after their informed consent had been obtained. They underwent clinical examinations at Hyogo Health Service Association (Kobe, Japan). None of the subjects were diagnosed as having gout or renal failure ( $\geq 1.5 \mathrm{mg} / \mathrm{dl}$ of serum creatinine). 
Body mass index (BMI) was computed as weight $(\mathrm{kg})$ divided by height $\left(\mathrm{m}^{2}\right)$. Blood pressure was determined by standard sphygmomanometric procedures, with the subjects in a relaxed state. Data on alcohol intake and smoking habits were obtained by interview. The subjects were asked to quantify their consumption of alcohol in terms of the kind of alcoholic beverage usually drunk and the minimum consumption per week. Alcohol intakes were then converted into grams of alcohol per day. The number of cigarettes smoked per day was also noted.

Blood sample collection and DNA extraction

A venous blood sample was drawn from each of the participants. DNA was extracted, using a SepaGene Kit (Sanko Junyaku, Tokyo, Japan), and stored at $-20^{\circ} \mathrm{C}$ until analysis. Serum was used for clinical chemistry laboratory examinations at Hyogo Health Service Association.

\section{MTHFR genotyping}

Polymerase chain reaction (PCR) was carried out with a PCR thermal cycler (TP2000; Takara Biomedicals, Kyoto, Japan). Thirty microliters of reaction mixture contained 200 ng of genomic DNA in $1 \times$ Expand High Fidelity buffer (Boehringer Mannheim, Amsterdam, Netherlands) with $1.5 \mathrm{mM} \mathrm{MgCl}_{2}, 250 \mu \mathrm{M}$ dNTPs, $0.5 \mu \mathrm{M}$ primers, and 0.7 units of Expand High Fidelity PCR System Enzyme Mix (Boehringer Mannheim). The sequences of the primers were as follows: 5'-TGAAGGAGGTGTCTGCGGGA-3' and 5'-AGGACGGTGCGGTGAGAGTG-3' (Frosst et al. 1995). The conditions for PCR included initial denaturation at $94^{\circ} \mathrm{C}$ for $3 \mathrm{~min}$, followed by 30 cycles of denaturation at $94^{\circ} \mathrm{C}$ for $1 \mathrm{~min}$, annealing at $55^{\circ} \mathrm{C}$ for $2 \mathrm{~min}$, extension at $72^{\circ} \mathrm{C}$ for $3 \mathrm{~min}$, and a final extension at $72^{\circ} \mathrm{C}$ for $7 \mathrm{~min}$. The amplified products were digested with Hinf I (New England Biolabs, Beverly, MA, USA) at $37^{\circ} \mathrm{C}$ for $4 \mathrm{~h}$. The C-to-T transition creates a new Hinf I site. The digested products were electrophoresed in a $3 \%$ agarose gel.

\section{Biochemical determinations}

The following clinical chemistry variables were determined in serum by standard enzymatic methods: total cholesterol, high-density lipoprotein (HDL) cholesterol, triglycerides, glucose, uric acid, creatinine, urea, total protein, alanine aminotransferase, aspartate aminotransferase, $\gamma$-glutamyltranspeptidase, and alkaline phosphatase. For each subject, a whole blood cell count was taken.

\section{Statistical analyses}

In the determination of MTHFR genotypes, HardyWeinberg equilibrium was assessed by $\chi^{2}$ analysis. For statistical purposes, all variables showing a non-Gaussian distribution were logarithmically transformed. Analysis of variance (ANOVA) and Scheffe's $F$-test were used to compare the means among subjects divided according to MTHFR genotype. The odds ratio and $95 \%$ confidence interval $(95 \% \mathrm{CI})$ were calculated to estimate the relative risk of hyperuricemia associated with MTHFR genotype. Study variables were correlated with uric acid levels, using Pearson's correlation coefficient test or Spearman's correlation coefficient by rank test. Multiple regression analysis was performed, using uric acid as the dependent variable, and a group of significantly correlated parameters (by Pearson's or Spearman's analysis) as independent variables. In the analyses, MTHFR genotypes were designated as follows: $\mathrm{C} / \mathrm{C}=0, \mathrm{C} / \mathrm{T}=1, \mathrm{~T} / \mathrm{T}=2$ (Motti et al. 1998). These values reflected the copy number of $\mathrm{T}$ alleles in a subject. The analyses were performed using the StatView statistical package (Abacus Concepts, Berkeley, CA, USA) and Microsoft Excel (Microsoft, Redmond, WA, USA).

\section{Results}

Study population

Table 1 shows some baseline clinical and laboratory data for the subjects who participated in the study. The mean age of the subjects was 52.6 years (range, 40-79 years). The percentages of subjects with hypertension (systolic blood pressure, $\geq 160 \mathrm{mmHg}$ or diastolic blood pressure, $\geq 95 \mathrm{mmHg}$ ), diabetes mellitus or impaired glucose tolerance (Hemoglobin Aic [HbAic], $\geq 6.5 \%$ ), hypercholesterolemia (plasma total cholesterol, $\geq 220 \mathrm{mg} / \mathrm{dl}$ ), and hyperglyceridemia (triglycerides, $\geq 150 \mathrm{mg} / \mathrm{dl}$ ) were $12.5 \%, 5.9 \%$, $27.7 \%$, and $29.1 \%$, respectively.

\section{Distribution of MTHFR genotypes}

The distribution of the MTHFR genotypes was: $\mathrm{C} / \mathrm{C}, 41 \%$ (95\% CI, 35\%-47\%); C/T, $45 \%$ (95\% CI, $40 \%-51 \%$ ); and

Table 1. Clinical data for the subjects enrolled in the study

\begin{tabular}{lccc}
\hline Variable & Mean & SD & Range \\
\hline Age (years) & 52.6 & 8.8 & $40-79$ \\
BMI (kg/m ) & 23.3 & 2.73 & $16.1-30.6$ \\
Systolic blood pressure (mmHg) & 121.4 & 18.6 & $86-182$ \\
Diastolic blood pressure (mmHg) & 79.1 & 12.9 & $48-122$ \\
Total cholesterol (mg/dl) & 200.6 & 33.1 & $96-301$ \\
HDL-cholesterol (mg/dl) & 56.9 & 16.1 & $26-129$ \\
Log triglycerides (mg/dl) & 2.1 & 0.24 & $1.5-2.9$ \\
Glucose (mg/dl) & 104.7 & 24.7 & $77-299$ \\
Total protein (g/dl) & 7.25 & 0.39 & $5.9-8.4$ \\
Creatinine (mg/dl) & 0.94 & 0.14 & $0.6-1.5$ \\
Blood urea nitrogen (mg/dl) & 15.0 & 3.1 & $7.9-27.6$ \\
Uric acid (mg/dl) & 5.92 & 1.36 & $2.4-10.8$ \\
Hematocrit (\%) & 44.2 & 3.0 & $35.8-51.7$ \\
Alkaline phosphatase (IU/l) & 142.1 & 39.6 & $70-332$ \\
HbAic (\%) & 5.05 & 0.91 & $3.7-10.3$ \\
Alcohol (g/day) & 24.5 & 21.8 & $0-99.4$ \\
Smoking (cigarettes/day) & 10.9 & 14.2 & $0-60$ \\
\hline BMI, Body mass & &
\end{tabular}

$\overline{\text { BMI, Body mass index; HDL, high-density lipoprotein; HbAic, Hemo- }}$ globin Aic 
$\mathrm{T} / \mathrm{T}, 14 \%$ (95\% CI, $10 \%-18 \%)$. The proportions of the MTHFR genotypes did not differ significantly from the values expected for the Hardy-Weinberg equilibrium $\left(\chi^{2}=\right.$ 0.23 ; degrees of freedom $[\mathrm{df}]=1 ; P=0.63)$. Allele frequencies were 0.63 (95\% CI, 0.59-0.68) for the C allele and 0.37 (95\% CI: 0.32-0.41) for the T allele. These findings were consistent with previous reports from Japan (Nishio et al. 1996; Morita et al. 1998; Ou et al. 1998).

Physical and biochemical variables in subjects grouped by MTHFR genotype

The distribution of physical and biochemical variables, in subjects grouped by MTHFR genotype, is shown in Table 2. For all variables, except for uric acid and creatinine, there were no significant differences between the groups of subjects with different MTHFR genotypes.

MTHFR genotype and uric acid level

The serum uric acid levels for each genotype are shown in
Table 2. The serum uric acid levels in the subjects with different MTHFR genotypes differed significantly $(F=$ 4.4575; $P=0.012)$. Homozygotes for the MTHFR mutation had a significantly higher mean uric acid level (6.39 \pm $1.25 \mathrm{mg} / \mathrm{dl}$; mean $\pm \mathrm{SD}$ ) than did those without the mutation $(5.67 \pm 1.34 \mathrm{mg} / \mathrm{dl}$; Scheffe's $F$-test, $P=0.018)$, while heterozygotes had an intermediate value $(6.00 \pm 1.38 \mathrm{mg} /$ $\mathrm{dl}$ ). There was a trend towards increasing uric acid levels as the number of copies of the T allele increased.

As shown in Table 3, subjects were classified into two groups based on uric acid levels: a low uric acid group $(<7.0 \mathrm{mg} / \mathrm{dl})$ and a high uric acid group $(\geq 7.0 \mathrm{mg} / \mathrm{dl})$. The value of $7.0 \mathrm{mg} / \mathrm{dl}$ was the upper limit of the normal range of serum uric acid in males in our laboratory and was used as the cut-off value. The genotype frequencies differed significantly between the two groups $\left(\chi^{2}=8.549 ; \mathrm{df}=2\right.$; $P=0.014)$. The $\mathrm{T} / \mathrm{T}$ genotype frequency in the high uric acid group was twice as high as that in low uric acid group $\left(\chi^{2}=4.31 ; \mathrm{df}=1 ; P=0.038\right)$. The T allele frequency was also significantly greater in the high uric acid group than in the low uric acid group $\left(\chi^{2}=8.78 ; \mathrm{df}=1 ; P=\right.$ $0.003)$.

Table 2. Clinical data for subjects grouped by methylene tetrahydrofolate reductase (MTHFR) genotype

\begin{tabular}{lcccc}
\hline & \multicolumn{2}{c}{ MTHFR genotypes } & \\
\cline { 2 - 3 } Variable & $\mathrm{C} / \mathrm{C}^{\mathrm{a}}(n=111)$ & $\mathrm{C} / \mathrm{T}^{\mathrm{a}}(n=122)$ & $\mathrm{T} / \mathrm{T}^{\mathrm{a}}(n=38)$ & $P$ value \\
\hline Age (years) & $53.9 \pm 8.4$ & $51.2 \pm 7.9$ & $52.4 \pm 7.9$ & 0.0745 \\
BMI (kg/m $)$ & $23.3 \pm 2.8$ & $23.2 \pm 2.4$ & $23.6 \pm 2.4$ & 0.8022 \\
Systolic blood pressure (mmHg) & $121.2 \pm 19.3$ & $120.2 \pm 18.8$ & $125.6 \pm 18.8$ & 0.2917 \\
Diastolic blood pressure (mmHg) & $78.7 \pm 12.9$ & $78.4 \pm 14.2$ & $82.2 \pm 14.2$ & 0.2782 \\
Total cholesterol (mg/dl) & $198.8 \pm 32.2$ & $201.6 \pm 35.6$ & $203.5 \pm 35.6$ & 0.6878 \\
HDL-cholesterol (mg/dl) & $55.2 \pm 16.2$ & $58.2 \pm 14.3$ & $60.0 \pm 14.3$ & 0.3421 \\
Log triglycerides (mg/dl) & $2.1 \pm 0.3$ & $2.0 \pm 0.2$ & $2.0 \pm 0.2$ & 0.2050 \\
Glucose (mg/dl) & $102.8 \pm 30.3$ & $107.0 \pm 18.6$ & $104.3 \pm 18.6$ & 0.4349 \\
Total protein (g/dl) & $7.2 \pm 0.4$ & $7.3 \pm 0.4$ & $7.3 \pm 0.4$ & 0.9787 \\
Creatinine (mg/dl) & $0.92 \pm 0.12$ & $0.95 \pm 0.13$ & $1.00 \pm 0.13$ & $0.0055^{*}$ \\
Blood urea nitrogen (mg/dl) & $14.7 \pm 2.9$ & $15.1 \pm 3.1$ & $15.0 \pm 3.1$ & 0.5937 \\
Uric acid (mg/dl) & $5.67 \pm 1.33$ & $6.00 \pm 1.25$ & $6.39 \pm 1.25$ & $0.0123^{*}$ \\
Hematocrit (\%) & $44.0 \pm 2.9$ & $44.6 \pm 3.0$ & $43.6 \pm 2.6$ & 0.1525 \\
Alkaline phosphatase (IU/l) & $139.3 \pm 37.6$ & $145.3 \pm 35.3$ & $140.3 \pm 35.3$ & 0.4906 \\
HbAic (\%) & $5.1 \pm 1.0$ & $5.3 \pm 0.8$ & $5.0 \pm 0.8$ & 0.7146 \\
Alcohol (g/day) & $23.7 \pm 22.1$ & $26.0 \pm 21.9$ & $20.4 \pm 18.0$ & 0.3808 \\
Smoking (cigarettes/day) & $11.6 \pm 15.9$ & $11.0 \pm 14.7$ & $8.3 \pm 14.7$ & 0.4779 \\
\hline
\end{tabular}

$* P<0.05$

The values in different $M T H F R$ genotypes (means $\pm \mathrm{SD}$ ) were compared by analysis of variance (ANOVA)

${ }^{a}$ See text for explanation of genotypes

Table 3. Odds ratios of hyperuricemia associated with $M T H F R$ genotypes

\begin{tabular}{lllll}
\hline & \multicolumn{2}{l}{ MTHFR genotype } & \\
\cline { 2 - 5 } Groups & $\mathrm{C} / \mathrm{C}$ & $\mathrm{C} / \mathrm{T}$ & $\mathrm{T}^{\mathrm{a}} \mathrm{T}^{\mathrm{b}}$ & $\begin{array}{l}\text { T allele } \\
\text { frequency }^{\mathrm{c}}\end{array}$ \\
\hline Low uric acid level $(<7.0 \mathrm{mg} / \mathrm{dl})$ & $96(45.1 \%)$ & $92(43.2 \%)$ & $25(11.7 \%)$ & 0.33 \\
High uric acid level $(\geqq 7.0 \mathrm{mg} / \mathrm{dl})$ & $15(25.9 \%)$ & $30(51.7 \%)$ & $13(22.4 \%)$ & 0.48 \\
Odds ratio (95\% CI) & 1.0 & $2.09(1.05-4.13)$ & $3.33(1.40-7.89)$ & \\
\hline
\end{tabular}

$\mathrm{CI}$, Confidence interval

${ }^{\mathrm{a}} \chi^{2}=8.549 ; \mathrm{df}=2 ; P=0.014 ;$ genotype frequencies differed significantly in the two groups

${ }^{\mathrm{b}} \chi^{2}=4.31 ; \mathrm{df}=1 ; P=0.038 ; \mathrm{T} / \mathrm{T}$ genotype frequency was higher in the high uric acid group than in the low uric acid group

${ }^{c} \chi^{2}=8.78 ; \mathrm{df}=1 ; P=0.003 ;$ T allele frequency was higher in the high uric group than in the low uric acid group 
Table 4. Correlation coefficient ${ }^{\mathrm{a}}$ between different variables and uric acid levels

\begin{tabular}{lrc}
\hline & $r$ & $P$ value \\
\hline MTHFR & $0.177^{\mathrm{b}}$ & $0.0036^{*}$ \\
Age (years) & 0.042 & 0.4938 \\
BMI (kg/m ${ }^{2}$ ) & 0.293 & $<0.0001^{*}$ \\
Systolic blood pressure (mmHg) & 0.159 & $0.0089^{*}$ \\
Diastolic blood pressure (mmHg) & 0.290 & $<0.0001^{*}$ \\
Total cholesterol (mg/dl) & 0.026 & 0.6740 \\
HDL-cholesterol (mg/dl) & -0.184 & $0.0023^{*}$ \\
Log triglycerides (mg/dl) & 0.247 & $<0.0001^{*}$ \\
Glucose (mg/dl) & -0.105 & 0.0835 \\
Total protein (g/dl) & 0.076 & 0.2097 \\
Creatinine (mg/dl) & 0.328 & $<0.0001^{*}$ \\
Blood urea nitrogen (mg/dl) & 0.055 & 0.3685 \\
Hematocrit (\%) & 0.128 & $0.0368^{*}$ \\
Alkaline phosphatase (IU/l) & -0.125 & $0.0393^{*}$ \\
HbAic (\%) & -0.128 & $0.0368^{*}$ \\
Alcohol (g/day) & 0.044 & 0.4730 \\
Smoking (cigarettes/day) & -0.125 & $0.0401^{*}$ \\
\hline
\end{tabular}

$* P<0.05$

${ }^{a}$ Pearson's coefficient, unless otherwise indicated

${ }^{\text {b}}$ Spearman's coefficient

The calculated odds ratios and $95 \% \mathrm{CI}$ for the C/T genotype were 2.09 (1.05-4.13) and 3.33 (1.40-7.89) for the T/T genotype, compared with the $\mathrm{C} / \mathrm{C}$ genotype (Table 3$)$. Both of these effects were significant $(P=0.03$ and $P=0.005$, respectively), suggesting a codominant effect of the $\mathrm{T}$ allele on the risk of hyperuricemia.

\section{Univariate regression analyses}

On univariate analysis, serum uric acid showed a correlation with MTHFR genotype (number of copies of $\mathrm{T}$ allele per subject), BMI, systolic blood pressure (SBP), diastolic blood pressure (DBP), HDL-cholesterol, log-triglycerides, creatinine, hematocrit, alkaline phosphatase, HbAic, and smoking habits (Table 4). No relationship was found between uric acid level and other factors (age, total cholesterol, glucose, total protein, blood urea nitrogen, and alcohol consumption).

To exclude the possible biases caused by the presence of subjects with hypertension, diabetes mellitus or impaired glucose tolerance, hypercholesterolemia, and hyperglyceridemia, subjects with each of these conditions were left out of the list in turn. Leaving out subjects with any of these conditions did not change the results as to MTHFR genotype: the correlation coefficients between $M T H F R$ genotype and uric acid level fluctuated between 0.167 and 0.220 , and their $P$ values remained below 0.001 . The same could be said of creatinine, BMI, DBP, log-triglycerides, and HDL-cholesterol. Their significant correlation with uric acid level did not disappear even after we omitted the data that might be potential sources of bias.

\section{Multiple regression analyses}

To assess the independent contribution of the variables to serum uric acid levels, multiple regression analyses were
Table 5. Multiple regression analysis using serum uric acid as dependent variable

\begin{tabular}{lrr}
\hline & St. $\beta$ & $P$ value \\
\hline Creatinine (mg/dl) & 0.245 & $<0.0001^{*}$ \\
Diastolic blood pressure (mmHg) & 0.202 & $0.0168^{*}$ \\
Log triglycerides (mg/dl) & 0.156 & $0.0128^{*}$ \\
BMI (kg/m $)$ & 0.137 & $0.0337^{*}$ \\
$M T H F R$ & 0.109 & $0.0483 *$ \\
HbAic $(\%)$ & -0.097 & 0.0829 \\
Hematocrit (\%) & 0.000 & 0.9984 \\
Alkaline phosphatase (IU/l) & -0.067 & 0.2331 \\
HDL-cholesterol (mg/dl) & -0.076 & 0.2311 \\
Systolic blood pressure (mmHg) & -0.023 & 0.7759 \\
Smoking (cigarettes/day) & -0.097 & 0.1069 \\
$R$ & 0.522 & $<0.0001$ \\
\hline$* P<0.05$ & & \\
St. $\beta$, standardized $\beta$ coefficient & &
\end{tabular}

done, including the variables that were significantly associated with serum uric acid on univariate analyses. As shown in Table 5, creatinine, DBP, log-triglycerides, BMI, and MTHFR genotype were found to be independently associated with serum uric acid levels. Systolic blood pressure, HDL-cholesterol, and alkaline phosphatase showed no consistent association with uric acid level.

\section{Discussion}

Several studies of twins, as well as epidemiological data about ethnic groups, have suggested that genetic factors intervene in serum uric acid level (Whitfield and Martin 1983; Emmerson et al. 1992; Tuomilehto et al. 1988). However, only two genetic disorders in which germline mutations cause hyperuricemia have been identified: hypoxanthine-guanine phosphoribosyltransferase (HPRT) deficiency (Seegmiller et al. 1967) and mutant phosphoribosylpyrophosphate (PRPP) synthetase (Sperling et al. 1973; Akaoka et al. 1981).

We have identified one of the genetic factors, the C677T MTHFR mutation, that is associated with hyperuricemia in elderly men. The C677T MTHFR mutation is an independent risk factor for vascular diseases. Recent studies have suggested that elevated serum uric acid predicts ischemic heart disease and stroke (Persky et al. 1979; Okada et al. 1982; Brand et al. 1985; Freedman et al. 1995; Wannamethee et al. 1997; Lehto et al. 1998; Culleton et al. 1999), although uric acid was thought to be an inert endproduct of purine metabolism without physiological significance, except in gouty diathesis. Therefore, the C677T MTHFR mutation may be a risk factor that is involved in multiple metabolic pathways related to vascular diseases.

In this study dealing with elderly men, a dose-dependent relationship was demonstrated between the number of copies of the T allele of the MTHFR gene and serum uric acid concentration (Table 2). Compared with the low uric acid group, the prevalence of the $\mathrm{T} / \mathrm{T}$ genotype and the frequency of the $\mathrm{T}$ allele were higher in the group with 
elevated uric acid levels. The calculated odds ratio and $95 \%$ $\mathrm{CI}$ of hyperuricemia showed an increased risk for the prevalence of the $\mathrm{C} / \mathrm{T}$ and $\mathrm{T} / \mathrm{T}$ genotype, compared with the $\mathrm{C} / \mathrm{C}$ genotype (Table 3). Multivariate analysis also demonstrated that the C677T MTHFR mutation was an independent predictor of hyperuricemia (Table 5). However, there was no relationship between the MTHFR genotypes and serum uric acid levels in young men, young women, or elderly women in our preliminary study (data not shown).

It remains less clear how the mutated homozygosity ( $\mathrm{T} /$ T genotype) increases the serum uric acid level. Motti et al. (1998) presented two possible mechanisms. First, in subjects with the $\mathrm{T} / \mathrm{T}$ genotype, renovascular atherosclerosis or the complications of systemic vascular disease may decrease the renal clearance of uric acid, resulting in elevated serum uric acid levels. Second, adenosine originating from Sadenosyl-homocysteine, a precursor of homocysteine, could represent a link between the metabolic pathways of homocysteine and uric acid. These two mechanisms may work simultaneously in subjects with the $\mathrm{T} / \mathrm{T}$ genotype.

The question then arises as to how much the C677T MTHFR mutation does contribute to hyperuricemia. In order to answer this question, we compared the C677T MTHFR mutation with other risk factors for hyperuricemia, using multiple regression analysis. Four other factors were also shown to be associated with hyperuricemia in this study: creatinine, DBP, triglycerides, and BMI. Compared with these four factors, the C677T MTHFR mutation, itself, may contribute less to hyperuricemia, because it showed a lower standard partial regression coefficient (standardized $\beta$ coefficient) to serum uric acid, as shown in Table 5 .

To reduce the risk of vascular disorders in those who carry the C677T MTHFR mutation, especially mutated homozygotes, supplementation with folate, vitamin B12, and vitamin B6 has been recommended, because these micronutrients help to maintain the activity of the enzymes that metabolize homocysteine (Malinow 1994; Scott and Weir 1996). For the mutated homozygotes, strategies for lowering serum uric acid level, such as weight control and reducing the intake of foods containing purines, should be adopted to prevent hyperuricemia or gout. According to Motti et al. (1998), of the three genotypes, the mutated homozygotes showed the strongest correlation and the steepest slope of the regression line between serum uric acid and the logarithmically transformed value of plasma homocysteine.

Thus, we have demonstrated that mutation of the MTHFR gene may be a risk factor for hyperuricemia in elderly Japanese men. We have also identified four other factors associated with hyperuricemia in this study, and proposed a medical management strategy for those who are homozygous for the C677T MTHFR mutation.

\section{References}

Akaoka I, Fujimori S, Kamatani N, Takeuchi F, Yano E, Nishida Y, Hashimoto A, Horiuchi Y (1981) A gouty family with increased phosphoribosylpyrophosphate synthetase activity: case reports, familial studies, and kinetic studies of the abnormal enzyme. J Rheumatol 8:563-574

Araki A, Sako Y, Fukushima Y, Matsumoto M, Asada T, Kita T (1989) Plasma sulfhydryl-containing amino acids in patients with cerebral infarction and in hypertensive subjects. Atherosclerosis 79:139-146

Brand FN, McGee DL, Kannel WB, Stokes JD, Castelli WP (1985) Hyperuricemia as a risk factor of coronary heart disease: the Framingham Study. Am J Epidemiol 121:11-18

Christensen B, Frosst P, Lussier-Cacan S, Selhub J, Goyette P, Rosenblatt DS, Genest J Jr, Rozen R (1997) Correlation of a common mutation in the methylenetetrahydrofolate reductase gene with plasma homocysteine in patients with premature coronary artery disease. Arterioscler Thromb Vasc Biol 17:569-573

Coull BM, Malinow MR, Beamer N, Sexton G, Nordt F, de Garmo P (1990) Elevated plasma homocyst(e)ine concentration as a possible independent risk factor for stroke. Stroke 21:572-576

Culleton BF, Larson MG, Kannel WB, Levy D (1999) Serum uric acid and risk for cardiovascular disease and death: the Framingham Heart Study. Ann Intern Med 131:7-13

Emmerson BT, Nagel SL, Duffy DL, Martin NG (1992) Genetic control of the renal clearance of urate: a study of twins. Ann Rheum Dis 51:375-377

Evers S, Koch HG, Grotemeyer KH, Lange B, Deufel T, Ringelstein EB (1997) Features, symptoms, and neurophysiological findings in stroke associated with hyperhomocysteinemia. Arch Neurol 54:1276-1282

Freedman DS, Williamson DF, Gunter EW, Byers T (1995) Relation of serum uric acid to mortality and ischemic heart disease. The NHANES I Epidemiologic Follow-up Study. Am J Epidemiol 141:637-644

Frosst P, Blom HJ, Milos R, Goyette P, Sheppard CA, Matthews RG, Boers GJ, den Heijer M, Kluijtmans LA, van den Heuvel LP, Rozen R (1995) A candidate genetic risk factor for vascular disease: a common mutation in methylenetetrahydrofolate reductase. Nat Genet 10:111-113

Gudnason V, Stansbie D, Scott J, Bowron A, Nicaud V, Humphries S (1998) C677T (thermolabile alanine/valine) polymorphism in methylenetetrahydrofolate reductase (MTHFR): its frequency and impact on plasma homocysteine concentration in different European populations. EARS group. Atherosclerosis 136:347-354

Kang SS, Wong PW, Cook HY, Norusis M, Messer JV (1986) Proteinbound homocyst(e)ine. A possible risk factor for coronary artery disease. J Clin Invest 77:1482-1486

Lehto S, Niskanen L, Rönnemaa T, Laakso M (1998) Serum uric acid is a strong predictor of stroke in patients with non-insulin-dependent diabetes mellitus. Stroke 29:635-639

Malinow MR (1994) Homocyst(e)ine and arterial occlusive diseases. J Intern Med 236:603-617

Malinow MR, Levenson J, Giral P, Nieto FJ, Razavian M, Segond P, Simon A (1995) Role of blood pressure, uric acid, and hemorheological parameters on plasma homocyst(e)ine concentration. Atherosclerosis 114:175-183

Morita H, Kurihara H, Tsubaki S, Sugiyama T, Hamada C, Kurihara Y, Shindo T, Oh-hashi Y, Kitamura K, Yazaki Y (1998) Methylenetetrahydrofolate reductase gene polymorphism and ischemic stroke in Japanese. Arterioscler Thromb Vasc Biol 18:14651469

Motti C, Gnasso A, Bernardini S, Massoud R, Pastore A, Rampa P, Federici G, Cortese C (1998) Common mutation in methylenetetrahydrofolate reductase. Correlation with homocysteine and other risk factors for vascular disease. Atherosclerosis 139:377-383

Nishio H, Lee MJ, Fujii M, Kario K, Kayaba K, Shimada K, Matsuo M, Sumino K (1996) A common mutation in methylenetetrahydrofolate reductase gene among the Japanese population. Jpn J Hum Genet 41:247-251

Okada M, Ueda K, Omae T, Takeshita M, Hirota Y (1982) The relationship of serum uric acid to hypertension and ischemic heart disease in Hisayama population, Japan. J Chronic Dis 35:173-178

Ou T, Yamakawa-Kobayashi K, Arinami T, Amemiya H, Fujiwara H, Kawata K, Saito M, Kikuchi S, Noguchi Y, Sugishita Y, Hamaguchi H (1998) Methylenetetrahydrofolate reductase and apolipoprotein E polymorphisms are independent risk factors for coronary heart disease in Japanese: a case-control study. Atherosclerosis 137: $23-28$ 
Persky VW, Dyer AR, Stamler J, Idris-soven E, Shekelle RB, Schoenberger JA, Berkson DM, Lindberg HA (1979) Uric acid: a risk factor for coronary heart disease? Circulation 59:969-977

Reed D, Labarthe D, Stallones R (1972) Epidemiologic studies of serum uric acid levels among Micronesians. Arthritis Rheum 15:381-390

Scott J, Weir D (1996) Homocysteine and cardiovascular disease. Q J Med 89:561-563

Seegmiller JE, Rosenbloom FM, Kelley WN (1967) Enzyme defect associated with a sex-linked human neurological disorder and excessive purine synthesis. Science 155:1682-1684

Sperling O, Persky-Brosh S, Boer P, De Vries A (1973) Human erythrocyte phosphoribosylpyrophosphate synthetase mutationally altered in regulatory properties. Biochem Med 7:389-395

Tuomilehto J, Zimmet P, Wolf E, Taylor R, Ram P, King H (1988) Plasma uric acid level and its association with diabetes mellitus and some biologic parameters in a biracial population of Fiji. Am J Epidemiol 127:321-336

van der Put NMJ, Steegers-Theunissen RP, Frosst P, Trijbels FJM,
Eskes TKAB, van den Heuvel LP, Mariman ECM, den Heyer M, Rozen R, Blom HJ (1995) Mutated methylenetetrahydrofolate reductase as a risk factor for spina bifida. Lancet 346:1070-1071

van der Put NMJ, van den Heuvel LP, Steegers-Theunissen RP, Trijbels FJM, Eskes TKAB, Mariman ECM, den Heyer M, Blom HJ (1996) Decreased methylene tetrahydrofolate reductase activity due to the $677 \mathrm{C} \rightarrow \mathrm{T}$ mutation in families with spina bifida offspring. $\mathrm{J}$ Mol Med 74:691-694

van der Put NMJ, Gabreels F, Stevens EMB, Smeitink JA, Trijbels FJM, Eskes TKAB, van den Heuvel LP, Blom HJ (1998) A second common mutation in the methylenetetrahydrofolate reductase gene: an additional risk factor for neural-tube defects? Am J Hum Genet 62:1044-1051

Wannamethee SG, Shaper AG, Whincup PH (1997) Serum urate and the risk of major coronary heart disease events. Heart 78:147-153

Whitfield JB, Martin NG (1983) Inheritance and alcohol as factors influencing plasma uric acid levels. Acta Genet Med Gemellol Roma $32: 117-126$ 